\title{
Rancang Bangun Sistem Peringatan Dini Banjir Berdasarkan Tingkat Kekeruhan Air Hulu Sungai dengan Turbidity Sensor SEN0189 dan Transceiver nRF24L01+
}

\author{
Syafiq Ammari", Wildian, Harmadi** \\ Laboratorium Elektronika dan Instrumentasi, Jurusan Fisika \\ Fakultas Matematika dan Ilmu Pengetahuan Alam Universitas Andalas \\ Kampus UNAND Limau Manis, Padang, 25163 Indonesia \\ *syafiq.ammari97@gmail.com \\ **harmadi@fmipa.unand.ac.id
}

\begin{abstract}
ABSTRAK
Telah dilakukan rancang bangun sistem peringatan dini banjir berdasarkan tingkat kekeruhan air hulu sungai dengan turbidity sensor SEN0189 dan transceiver nRF24L01+. Alat yang dirancang terbagi menjadi unit transmitter dan unit receiver. Unit transmitter terdiri dari turbidity sensor SEN0189, modul Arduino UNO R3 dan transceiver nRF24L01+. Unit receiver terdiri dari LCD, transceiver nRF24L01+, modul Arduino UNO R3 dan buzzer. Sensor mengindra tingkat kekeruhan air kemudian nilainya ditransmisikan dari transmitter ke receiver oleh transceiver nRF24L01+. Data kekeruhan air diproses oleh mikrokontroler pada modul Arduino UNO R3 untuk ditampilkan pada LCD dan mengaktifkan peringatan melalui buzzer. Jarak maksimum transmisi data sejauh $500 \mathrm{~m}$ tanpa penghalang dan $300 \mathrm{~m}$ dengan penghalang berupa pepohonan. Hasil pengukuran oleh alat yang dirancang memiliki persentase kesalahan rata-rata sebesar $29,48 \%$ dibanding alat standar turbidimeter HACH $2100 \mathrm{~N}$. Nilai akurasi tertinggi diperoleh pada tingkat kekeruhan air di atas 390 NTU dengan persentase kesalahan kurang dari 5\%. Peringatan dini banjir diaktifkan ketika kekeruhan air di atas 467 NTU berupa nyala buzzer dan tulisan "BERPOTENSI BANJIR" pada LCD. Buzzer mati secara otomatis dan LCD menampilkan tulisan "NORMAL" ketika kekeruhan air kurang dari 467 NTU. Alat yang dirancang mampu menampilkan nilai kekeruhan air secara realtime dan memberi peringatan sesuai dengan tingkat kekeruhan air. Kata kunci: nRF24L01+, peringatan dini, tingkat kekeruhan air, transmisi data, turbidity sensor
\end{abstract}

\section{ABSTRACT}

A flood early warning system based on water turbidity level at river upstream using turbidity sensor SEN0189 and transceiver nRF24L01+ has been designed. The device consist of transmitter unit and receiver unit. Transmitter unit consist of SEN0189 turbidity sensor, Arduino UNO R3 module and $n R F 24 L 01+$ transceiver. Receiver unit consist of LCD, nRF24L01+ transceiver, Arduino UNO R3 module and buzzer. Sensor senses the water turbidity level then the value is transmitted from transmitter to receiver by $n R F 24 L 01+$ transceiver. Water turbidity data is processed by microcontroller at Arduino UNO R3 module in order to be displayed on LCD and turn the warning on using buzzer. The maximum data transmission distance is $500 \mathrm{~m}$ without barrier and $300 \mathrm{~m}$ with trees as barrier. The measurement result shows that device has 29,48\% error percentage that compared to the standard device turbidimeter HACH 2100N. The highest accuration is reached at water turbidity level above 390 NTU with error percentage less than 5\%. The flood early warning is activated when water turbidity above 467 NTU by turning on the buzzer and "BERPOTENSI BANJIR" words are showed on LCD. Buzzer turn off automatically and LCD shows "NORMAL" words when water turbidity less than 467 NTU. The device is able to showing the water turbidity value realtime and give the warning based on the water turbidity level.

Keywords:nRF24L01+, early warning, water turbidity level, data transmission, turbidity sensor

\section{PENDAHULUAN}

Wilayah Indonesia memiliki iklim tropis dengan curah hujan tinggi yang dapat memicu terjadinya bencana alam seperti banjir (BNPB, 2017). Banjir dapat terjadi secara tiba-tiba akibat hujan lebat disertai luapan air di daerah aliran sungai. Hujan lebat yang menimbulkan banjir dapat memicu longsoran lereng pada tebing (Mulyanto dkk., 2012). Longsoran lereng merupakan dampak dari erosi akibat air hujan yang membawa tanah, lumpur dan pasir sehingga menyebabkan peningkatan kekeruhan air sungai.

Peningkatan kekeruhan air sungai merupakan salah satu indikator peringatan dini adanya potensi banjir. BMKG (2018) menyatakan bahwa salah satu tanda akan terjadinya banjir yaitu air sungai tiba-tiba menjadi keruh serta mengalir bersama lumpur, pasir, dan 
ranting-ranting kayu. Kekeruhan air di hulu sungai meningkat seiring terjadinya pengikisan tanah akibat tingginya intensitas hujan. Intensitas hujan yang tinggi akan meningkatkan debit air di hulu sungai. Debit air yang tinggi akan mengalir ke hilir sungai sebagai banjir.

Air sungai ketika banjir tidak memiliki suatu nilai standar kekeruhan yang baku sehingga kekeruhan air banjir berbeda-beda untuk setiap sungai. Penelitian mengenai kekeruhan air banjir pernah dilakukan oleh LIPI terhadap air sungai Citarum ketika banjir tahun 2010 dengan nilai 467 NTU (LIPI, 2010). Nilai kekeruhan air sungai yang telah diukur ketika banjir dapat menjadi ambang batas nilai kekeruhan saat air sungai tersebut berpotensi mengalir sebagai air banjir.

Yuzria dkk. (2017) telah merancang sistem peringatan dini banjir menggunakan telemetri nirkabel. Sistem peringatan dini banjir yang telah mereka rancang menggunakan indikator ketinggian muka air dengan sensor ultrasonik HC-SR04. Prinsip kerja alat yang mereka rancang menjadi acuan sistem peringatan dini banjir berdasarkan peningkatan kekeruhan air hulu sungai. Faisal dkk. (2016) telah merancang sistem monitoring tingkat kekeruhan air secara realtime menggunakan sensor TSD-10. Alat yang dirancang berupa alat ukur untuk sistem monitoring kekeruhan air secara umum dan belum mengukur kekeruhan air pada objek tertentu seperti air sungai. Pesma dkk. (2017) telah merancang sistem telemetri nirkabel pemantauan tingkat kekeruhan air di PDAM. Alat yang dirancang menggunakan sensor TSD-10 yang dapat mengukur hingga 2600 NTU dan transceiver nRF24L01+. Alat yang dirancang otomatis mengirim nilai kekeruhan air secara nirkabel dan direkam datanya menggunakan PC.

Berdasarkan penelitian sebelumnya maka dirancanglah sistem peringatan dini banjir berdasarkan peningkatan kekeruhan air hulu sungai dengan turbidity sensor SEN0189 dan transceiver nRF24L01+. Turbidity sensor SEN0189 memiliki fungsi dan kemampuan yang sama dengan sensor TSD-10 tetapi penggunaannya lebih praktis. Pengiriman data nilai kekeruhan air di hulu sungai ditransmisikan dengan transceiver nRF24L01+ ke hilir sungai dan ditampilkan pada LCD. Buzzer di hilir sungai akan menyala ketika tingkat kekeruhan air hulu sungai telah melewati ambang batas nilai kekeruhan air yang telah diprogram. Peningkatan kekeruhan air di hulu sungai menjadi indikator yang efektif untuk sistem peringatan dini banjir dengan sistem telemetri nirkabel untuk jangkauan pengiriman sinyal yang lebih luas.

Kekeruhan adalah ukuran kejernihan air. Air dengan tingkat kekeruhan yang tinggi akan menyebabkan cahaya sulit melewati air tersebut. Pengukuran kekeruhan air menunjukkan jumlah cahaya yang dihamburkan oleh partikel-partikel di dalam air tersebut (Sadar dan Engelhardt, 2002). Cahaya dihamburkan oleh partikel-partikel seperti endapan lumpur, tanah liat, alga, materi organik, dan mikroorganisme yang berada di dalam air.

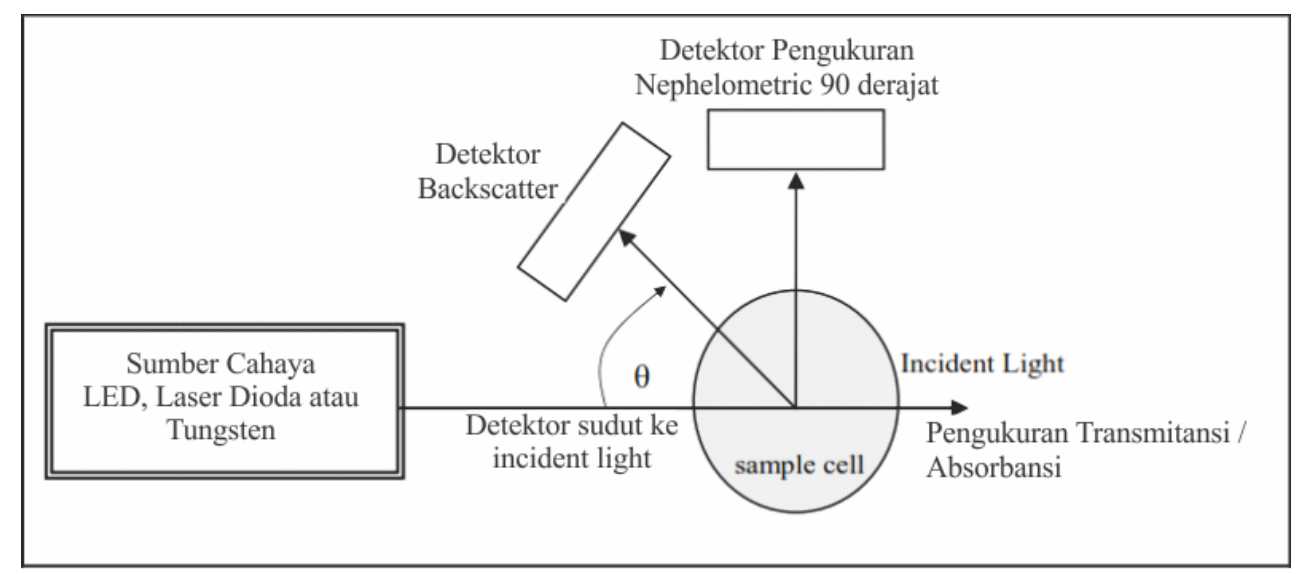

Gambar 1 Teknik pengukuran kekeruhan air

Pengukuran kekeruhan air dapat dilakukan dengan teknik Turbidimetry dan Nephelometry (Omar dan Matjafri, 2009). Gambaran teknik pengukuran kekeruhan air ditunjukkan oleh Gambar 1. Teknik Turbidimetry dilakukan dengan mengukur intensitas cahaya setelah ditransmisikan melewati sampel air. Teknik Turbidimetry digunakan untuk mengukur 
kekeruhan air dengan ukuran partikel penghambur yang lebih besar dari panjang gelombang cahaya yang ditransmisikan. Teknik Nephelometry dilakukan dengan mengukur intensitas cahaya yang dihamburkan oleh partikel terlarut di dalam air. Intensitas cahaya yang terhambur akan dideteksi pada sudut 90o. Sudut 90o merupakan sudut paling sensitif terhadap hamburan cahaya yang tidak memperhatikan ukuran partikel penghamburnya (Omar dan Matjafri, 2009). Teknik Nephelometry memiliki presisi dan sensitivitas yang lebih tinggi dari teknik Turbidimetry sehingga dapat digunakan untuk mengukur tingkat kekeruhan air yang rendah dengan ukuran partikel terlarut kecil (Lambrou dkk., 2009). Turbidity Sensor SEN0189 menggunakan teknik Nephelometry sehingga sensor dapat mengukur kekeruhan air yang rendah.

\section{METODE}

Rancang bangun sistem peringatan dini banjir berdasarkan peningkatan kekeruhan air hulu sungai dilakukan di Laboratorium Elektronika dan Instrumentasi Jurusan Fisika Universitas Andalas. Alat yang dirancang terbagi menjadi unit transmitter dan unit receiver. Unit transmitter terdiri dari turbidity sensor SEN0189, modul Arduino UNO R3 dan transceiver nRF24L01+. Unit receiver terdiri dari LCD, transceiver nRF24L01+, modul Arduino UNO R3 dan buzzer.

\subsection{Perancangan Diagram Blok Sistem}

Sistem terdiri dari unit transmitter dan unit receiver. Unit transmitter ditempatkan di daerah hulu sungai dan berperan sebagai pengirim data yang diindra oleh sensor. Unit receiver ditempatkan di daerah hilir sungai dan berperan sebagai penerima data. Data nilai kekeruhan air ditampilkan pada LCD disertai buzzer sebagai penanda peringatan dini banjir. Diagram blok sistem digambarkan pada Gambar 2.

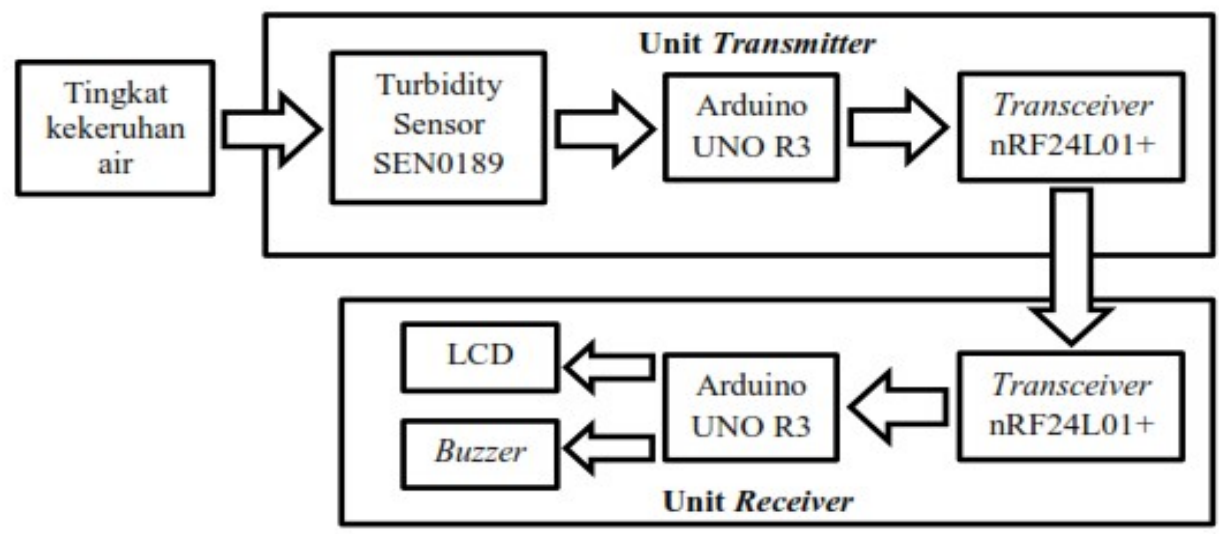

Gambar 2 Diagram blok sistem peringatan dini banjir

\subsection{Pengujian Sistem Peringatan Dini}

Pengujian sistem peringatan dini banjir dilakukan dalam skala laboratorium. Sistem diuji pada model sungai buatan dari pipa dengan air mengalir dan bahan pengotor untuk menghasilkan kekeruhan buatan. Kekeruhan buatan dihasilkan dari campuran tanah liat, pasir dan lumpur. Sampel air yang digunakan berupa air galon isi ulang, air sungai Batu Busuk di daerah Limau Manis Kota Padang pada keadaan normal, serta campuran $100 \mathrm{ml}$ air dan tanah liat dengan kadar $2.5 \mathrm{ml}, 5 \mathrm{ml}$ dan $10 \mathrm{ml}$. Sampel air diuji dengan alat standar turbidimeter HACH $2100 \mathrm{~N}$ di Laboratorium PDAM Kota Padang di daerah Gunung Pangilun.

Unit transmitter ditempatkan pada pangkal pipa yang dimodelkan sebagai hulu sungai. Sensor mengindra kekeruhan air di pangkal pipa dan data nilai kekeruhannya dikirim ke unit receiver di ujung pipa. Pengukuran kekeruhan air oleh sensor dilakukan secara dinamik dan nilai kekeruhan air yang terukur langsung dikirimkan ke unit receiver. Unit receiver memproses data yang diterima dari unit transmitter dan menampilkan nilai kekeruhan air di hulu sungai pada LCD. Jarak maksimum transmisi data dari transmitter ke receiver tanpa penghalang sejauh $500 \mathrm{~m}$ dan ketika terdapat penghalang berupa pepohonan sejauh $300 \mathrm{~m}$. 


\section{HASIL DAN DISKUSI}

\subsection{Pengujian Kekeruhan Air dengan Turbidity Sensor SEN0189}

Alat yang dirancang menggunakan turbidity sensor SEN0189 untuk mengindra kekeruhan air. Sensor mengkonversi nilai kekeruhan air menjadi besaran fisis berupa tegangan. Nilai tegangan keluaran sensor menjadi data masukan yang diolah oleh mikrokontroler sehingga alat dapat mengukur kekeruhan air. Nilai kekeruhan air yang diukur oleh alat yang dirancang, untuk sampel kekeruhan air yang sama, dibandingkan dengan nilai yang terukur pada alat standar turbidimeter HACH 2100N. Data perbandingan hasil pengukuran kekeruhan air oleh alat yang dirancang ditunjukkan oleh Tabel 1 .

Tabel 1 Hasil pengukuran kekeruhan air

\begin{tabular}{|c|c|c|}
\hline \multicolumn{2}{|c|}{ Kekeruhan Air (NTU) } & \multirow{2}{*}{$\begin{array}{l}\text { Nilai Persentase } \\
\text { Kesalahan }(\%)\end{array}$} \\
\hline $\begin{array}{l}\text { Alat Standar } \\
\text { (HACH 2100N) }\end{array}$ & Alat yang Dirancang & \\
\hline 0,38 & 44,35 & 115,71 \\
\hline 1,61 & 51,58 & 31,04 \\
\hline 390 & 520,16 & 0,33 \\
\hline 921 & 934,97 & 0,02 \\
\hline 2227 & 2940,17 & 0,32 \\
\hline \multicolumn{2}{|c|}{ Nilai Persentase Kesalahan Rata-Rata (\%) } & 29,48 \\
\hline
\end{tabular}

Nilai persentase kesalahan rata-rata alat yang dirancang terhadap alat standar sebesar $29,48 \%$. Hal ini disebabkan oleh rentang nilai antar sampel berjauhan sehingga nilai persentase kesalahan yang diperoleh berbeda-beda untuk setiap sampel. Sampel air dengan nilai kekeruhan air rendah yaitu 0,38 NTU dan 1,61 NTU memiliki nilai persentase kesalahan yang cendrung tinggi (lebih besar dari 5\%). Sampel air dengan nilai kekeruhan diatas 390 NTU memiliki nilai persentase kesalahan yang rendah (lebih kecil dari 5\%). Hal ini menunjukkan bahwa alat yang dirancang akurat untuk mengindra kekeruhan air di atas 390 NTU.

\subsection{Pengujian Sistem Peringatan Dini Secara Keseluruhan}

Pengujian sistem peringatan dini secara keseluruhan dilakukan untuk menguji kemampuan alat yang dirancang agar dapat bekerja sesuai tujuan. Alat yang dirancang dapat memberi peringatan ketika kekeruhan air di hulu sungai telah meningkat dan melewati nilai ambang batas kekeruhan yang telah diprogram. Ambang batas nilai kekeruhan yang digunakan yaitu 467 NTU sesuai dengan nilai kekeruhan air banjir di sungai Citarum yang pernah diukur oleh LIPI pada tahun 2010. Pengujian dilakukan dengan sampel air yang telah diuji dengan alat standar HACH 2100N. Data hasil pengujian alat secara keseluruhan ditunjukkan oleh Tabel 2.

Tabel 2 Hasil Pengujian Sistem Peringatan Dini Banjir

\begin{tabular}{ccccc}
\hline & & \multicolumn{2}{c}{ Penampil LCD } & Buzzer \\
\cline { 3 - 4 } No & $\begin{array}{c}\text { Kekeruhan Air } \\
\text { oleh Alat Standar } \\
\text { (NTU) }\end{array}$ & $\begin{array}{c}\text { Tampilan Nilai } \\
\text { Kekeruhan Air } \\
\text { (NTU) }\end{array}$ & $\begin{array}{c}\text { Tulisan } \\
\text { Peringatan Dini Banjir } \\
\text { (Berpotensi/Normal) }\end{array}$ & $\begin{array}{c}\text { Benyala/ } \\
\text { Tidak) }\end{array}$ \\
\hline 1 & 0,38 & 40,03 & Normal & Tidak \\
2 & 1,61 & 45,79 & Normal & Tidak \\
3 & 390 & 533,13 & Berpotensi & Menyala \\
4 & 921 & 1203,47 & Berpotensi & Menyala \\
5 & 2227 & 3235,33 & Berpotensi & Menyala \\
\hline
\end{tabular}

Hasil yang diperoleh dari pengujian alat secara keseluruhan menunjukkan bahwa alat yang dirancang berhasil memberi peringatan ketika kekeruhan air telah melewati 467 NTU. Nilai kekeruhan dikirim dari transmitter diolah oleh mikrokontroler di unit receiver sehingga LCD menampilkan nilai kekeruhan air disertai keterangan "NORMAL" atau "BERPOTENSI BANJIR". Ketika kekeruhan air sampel kurang dari 467 NTU, maka buzzer mati dan LCD 
menampilkan nilai kekeruhan air disertai tulisan "NORMAL". Ketika kekeruhan air sampel lebih atau sama dengan 467 NTU, maka buzzer menyala dan LCD menampilkan nilai kekeruhan air disertai tulisan "BERPOTENSI BANJIR". Alat secara otomatis menyalakan dan mematikan peringatan seiring dengan perubahan tingkat kekeruhan air. Hal ini menunjukkan bahwa alat yang dirancang bekerja secara dinamik sesuai dengan kekeruhan air yang diindra oleh sensor.

Alat yang dirancang diuji dan disimulasikan pada model sungai yang dibuat dari pipa serta dilengkapi dengan pompa yang memompa air agar mengalir melewati pipa. Air yang jernih ditempatkan di penampungan air dan dipompa ke pangkal pipa yang dimisalkan sebagai hulu sungai. Sensor dan transmitter diposisikan di aliran air pada pangkal pipa. Receiver ditempatkan di ujung pipa yang dimisalkan sebagai hilir sungai. Receiver menerima data nilai kekeruhan air dari transmitter dan LCD menampilkan nilai kekeruhan air yang mengalir di dalam pipa secara realtime. Ketika pengotor berupa tanah liat dicampurkan ke dalam air di penampungan, maka kekeruhan air yang mengalir di dalam pipa dan nilai kekeruhan air yang ditampilkan pada LCD berangsur-angsur meningkat. Hal ini membuktikan bahwa alat yang dirancang dapat bekerja secara realtime dan dinamik.

\section{KESIMPULAN}

Berdasarkan penelitian dan perancangan yang telah dilakukan, dapat disimpulkan bahwa alat yang dirancang berhasil memberi peringatan dini banjir sesuai tingkat kekeruhan air yang diindra oleh sensor. Data nilai kekeruhan air berhasil ditransmisikan secara nirkabel dari transmitter ke receiver dengan jarak maksimum $500 \mathrm{~m}$ tanpa penghalang dan $300 \mathrm{~m}$ dengan penghalang berupa pepohonan. Alat yang dirancang mampu mengkonversi tegangan keluaran sensor menjadi nilai kekeruhan air dalam satuan NTU dengan persentase kesalahan rata-rata sebesar 29,48\% dibanding alat standar turbidimeter $\mathrm{HACH} 2100 \mathrm{~N}$. Nilai akurasi tertinggi diperoleh saat alat mengindra kekeruhan air di atas 390 NTU dengan persentase kesalahan kurang dari 5\%. Alat yang dirancang mampu bekerja secara dinamik sesuai tingkat kekeruhan air dan hasil pengukurannya ditampilkan secara realtime.

\section{DAFTAR PUSTAKA}

BMKG, Air Sungai Keruh Salah Satu Tanda Potensi Banjir Bandang, http://m.cnnindonesia.com (16 Oktober 2018).

BNPB, Buku Saku Tanggap Tangkas Tangguh Menghadapi Bencana (Pusat Data Informasi dan Humas Badan Nasional Penanggulangan Bencana, Jakarta, 2017).

Faisal, M., Harmadi, Puryanti, D., Perancangan Sistem Monitoring Tingkat Kekeruhan Air Secara Real Time Menggunakan Sensor TSD-10, Jurnal Ilmu Fisika 8(1), 9-16 (2016).

Lambrou, T.P., Anastasiou, C.C., Panayiotou, C.G., A Nephelometic Turbidity System for Monitoring Residental Drinking Water Quality, Sensor Applications Experimentatation and Logistics 2(9), 43-45 (2008).

LIPI, Unit Pengolah Air Banjir Menjadi Air Bersih dan Layak Minum, http://www.fisika.lipi.go.id (8 April 2010).

Mulyanto, Parikesit, N.A., Utomo, H., Petunjuk Tindakan Dan Sistem Mitigasi Banjir Bandang (Direktorat Sungai dan Pantai Kementrian Pekerjaan Umum, Semarang, 2012).

Omar, A.F., Matjafri, M.Z., Turbidimeter Design and Analysis: A Review on Optical Fiber Sensors for the Measurement of Water Turbidity, Sensors 9, 8311-8335 (2009).

Pesma, R.A., Harmadi, Dahlan, D., Wildian, Syafrialdi, R., Yuzria, H.O., Rizky, A.R., Rancang Bangun Sistem Telemetri Nikabel Pemantauan Tingkat Kekeruhan Air Di PDAM Menggunakan Transceiver nRF24L01+ Dan Arduino UNO R3, Jurnal Ilmu Fisika 9(1), 15-25 (2017).

Sadar, M.J., Engelhardt, T.L., Determining Correlation of Nephelometric Turbidity Measurement to Suspended Solids in Industrial Samples (Hach Company, Colorado, 2002).

Yuzria, H.O., Pesma, R.A., Dahlan, D., Harmadi, Shadri, M., Wildian, Rancang Bangun Sistem Peringatan Dini Banjir Menggunakan Telemetri Nikabel Dengan Transceiver nRF24L01+, Jurnal Ilmu Fisika 9(1), 57-67 (2017). 